\title{
Titanium Carbide Effects on the Fracture of Inconel 100-A Case Study
}

\author{
Daniel Moreno ${ }^{\mathbb{B}}$, Ori Kam, Boris Wolfman, Orel Nafman, Shir Abrahami, Ariel Cohen, \\ Yochanan Nachmana, Zion Harush, Moshe Shapira
}

Bet Shemesh Engines LTD, FAA \& EASA, Bet Shemesh, Israel

Email: danielm@bsel.co.il

How to cite this paper: Moreno, D., Kam O., Wolfman, B., Nafman, O., Abrahami, S., Cohen, A., Nachmana, Y., Harush, Z. and Shapira, M. (2021) Titanium Carbide Effects on the Fracture of Inconel 100-A Case Study. Journal of Minerals and Materials Characterization and Engineering, 9, 432-443.

https://doi.org/10.4236/jmmce.2021.95029

Received: April 23, 2021

Accepted: August 29, 2021

Published: September 1, 2021

Copyright $\odot 2021$ by author(s) and Scientific Research Publishing Inc. This work is licensed under the Creative Commons Attribution International License (CC BY 4.0).

http://creativecommons.org/licenses/by/4.0/

\begin{abstract}
Carbides and borides appear as minor phases in Inconel 100, although the carbon content $(0.18 \%)$ is relatively high in comparison to other nickel-base superalloys. The material properties of this alloy depend on a number of interrelated microstructural parameters, including the volume fraction of $\gamma$ to $\gamma$, grain size, elemental distribution, and precipitation of carbides and borides. This study presents a characterization and a failure analysis of Inconel 100 samples loaded to fracture at $760^{\circ} \mathrm{C}$ and an examination of their fractography. Chemical analysis, optical metallography, SEM and EDS were used for the characterization of the unusual areas of fracture that were found on the samples. The thermodynamic stability of $\mathrm{TiC}$ led to the conclusion that the possibility of creating very large, stable mono carbides, especially TiC carbide, during the production process is the reason for the short time to failure obtained in this work.
\end{abstract}

\section{Keywords}

Carbides, Borides

\section{Introduction}

Nickel-base superalloys are by far the preferred alloys for jet engine and gas turbine components that work at high temperature, with high and low cycle fatigue, under creep resistance and in hostile environments. These alloys are reinforced by precipitation hardening of a secondary phase in coherency with a metal matrix and by secondary phases as carbides and borides at the grain boundaries. The gamma matrix, $\gamma$, is an FCC nickel-base nonmagnetic phase that commonly contains a high percentage of solid-solution elements such as cobalt, iron, chromium, molybdenum, and tungsten [1]. Pure nickel does not show good me- 
chanical properties at high temperatures and has low creep strength. There are three factors that can explain the use of superalloys at very high temperatures: 1 ) the solubility of some alloying elements in the nickel matrix, such as cobalt, tantalum, tungsten chromium and others; 2) the tendency of aluminum and chromium additions to form $\mathrm{Al}_{2} \mathrm{O}_{3}$ and $\mathrm{Cr}_{2} \mathrm{O}_{3}$ that improve corrosion at high temperatures; and 3 ) the thermodynamic properties that create stable $\mathrm{Ni}_{3}(\mathrm{Al}, \mathrm{Ta}, \mathrm{Ti})$ gamma prime, $\gamma$, at work temperatures as a precipitation hardening component [1]. The metallurgic thermodynamic aspects of these alloys must be very well understood in order to obtain the required properties for good performance. The gamma prime, $\gamma$, is required to display high-temperature strength and creep resistance. This phase, created by a diffusion process during the heat treatment, is an intermetallic compound of nominal composition $\mathrm{Ni}_{3}(\mathrm{Al}, \mathrm{Ta}, \mathrm{Ti})$, which maintains its stability over a wide range of stresses and temperatures. The morphology of $\gamma$ precipitates in Ni-base superalloys forms a coherent mismatch in an FCC lattice. It is observed that when mismatches are around $0.5 \%$ and higher, $\gamma$ maintains a cuboidal structure, achieving high density in the matrix and improving the creep resistance. In some alloys containing niobium, gamma double prime, $\gamma^{\prime \prime}$ is obtained, forming a Body Centered Tetragonal (BCT) $\mathrm{Ni}_{3} \mathrm{Nb}_{\text {struc- }}$ ture [2], which can be coherent with the gamma matrix. This phase is responsible for very high strength at low to intermediate temperatures, but it is unstable at temperatures above $650^{\circ} \mathrm{C}$. Most of the superalloys have low carbon content or even traces of carbon in the case of single crystal superalloys. Carbon is added mainly to reinforce the grain boundaries by carbides. The thermodynamic process involved in the formation of the carbides is very similar to the process during the formation of the $\gamma$ precipitates. The first carbides (MC) are the mono-carbides, where the element $\mathrm{M}$ may be titanium, tantalum, hafnium, niobium or similar. During heat treatment and service, these $\mathrm{MC}$ carbides tend to transform and generate other carbides, such as $\mathrm{M}_{23} \mathrm{C}_{6}$ and $\mathrm{M}_{6} \mathrm{C}$. This thermodynamic process is carried out mainly at the grain boundaries during the heat treatment, but in some cases, also inside the grains [2]. These carbides are distributed heterogeneously throughout the alloy. TiC and $\mathrm{HfC}$ carbides are very stable compounds, and once they are formed it is very difficult to dissolve them in comparison to $\mathrm{M}(\mathrm{Cr}, \mathrm{Fe}, \mathrm{W}, \mathrm{Mo}$ and $\mathrm{Co}) . \mathrm{M}_{23} \mathrm{C}_{6}$ carbides are usually found at alloy grain boundaries as discontinuous particles, and have characteristic geometric forms. The carbon composition of the alloy effects the above-mentioned formation. The $\mathrm{MC}$ carbides are the nucleons of the $\mathrm{M}_{23} \mathrm{C}_{6}$ and $\mathrm{M}_{6} \mathrm{C}$ ones and due to thermodynamic reasons form during the solidification and the cooling casting. $\mathrm{MC}$ carbides transform to other phases, such as $\mathrm{M}_{23} \mathrm{C}_{6}$ between $760^{\circ} \mathrm{C}$ $980^{\circ} \mathrm{C}$ and $\mathrm{M}_{6} \mathrm{C}$ between $815^{\circ} \mathrm{C}-980^{\circ} \mathrm{C}$, according to the equations: $\mathrm{MC}+\gamma \rightarrow$ $\mathrm{M}_{23} \mathrm{C}_{6}$ or $\mathrm{M}_{6} \mathrm{C}+\gamma$. The morphology of these carbides strongly affects the properties of nickel alloys. On polycrystalline superalloys, the rupture strength is improved by the presence of discrete carbides along the grain boundary. However, due to the fact that those carbides have brittle characteristics, the failure can start either by the fracture or by a discontinuity of the carbide/matrix interface. Car- 
bides of the type $\mathrm{M}_{6} \mathrm{C}$ form at grain boundaries, and less often in the form of a Widmanstatten microstructure [3] [4]. Widmanstatten microstructures are rarely reported in the literature in relation to $\mathrm{M}_{6} \mathrm{C}$ carbide in Ni-base superalloys, but have been reported as a defect named $\eta$ [5]. This $\eta$ phase, characterized as a Geometrical Close Packed (GCP) phase, is a compound $\mathrm{Ni}_{3} \mathrm{Ti}$ with a hexagonal close-packed (HCP) lattice $\left(\mathrm{DO}_{22}\right)$.

$\mathrm{M}_{6} \mathrm{C}$ carbides have a complex cubic structure, and are formed when the molybdenum and/or tungsten content is higher than 6 to $8 \mathrm{wt} \%$ in the range of $815^{\circ} \mathrm{C}$ to $980^{\circ} \mathrm{C}$. These carbides avoid grain growth and control the final grain size. Recent experimental research on the composition of carbides after creep has shown that the MC carbide was altered substantially, with the Ta content decreasing and the $\mathrm{Hf}$ and $\mathrm{Zr}$ contents increasing, suggesting a beneficial effect of $\mathrm{Hf}$ and $\mathrm{Zr}$ additions on the stability of $\mathrm{MC}$ carbides. By contrast, $\mathrm{M}_{5} \mathrm{~B}_{3}$ borides were found to be microstructurally stable after creep and without substantial compositional changes. Borides at $850^{\circ} \mathrm{C}$ were found to coarsen, resulting in some cases into $\gamma$-depleted zones, where, however, no plate-like phases or cracks were observed [6].

Topologically Close-Packed (TCP) phases are plate-like or needle-like phases such as $\sigma$ and $\mu$ that may form for some compositions under certain conditions [7]. In some alloys, if the composition has not been carefully controlled, the undesirable phases can form either during heat treatment or, more commonly, during service. The TCP precipitates can reduce rupture strength and ductility. Nickel alloys are prone to the formation of $\sigma$ and $\mu$ phases, if the alloy contains a high level of elements like tantalum, niobium, chromium, tungsten, and molybdenum. The occurrence of platelet phases in polycrystalline, Directionally Solidified (DS) and Single Crystal (SC) turbine blades, vanes, and integral wheels were investigated elsewhere [8]. Examples of platelet phases in turbine components made with low carbon PWA1480 (or PWA1483, AF56, or SX792), IN792 + Hf, 1N939, 1N6203, and GTDlll alloys were also reported [8]. For IN792 + Hf, IN939 and GTDIll the phases formed internally, and for most of the alloys, the phases also formed by reaction with the ceramic shell or face coat, or from local segregation. All of these alloys have $8-18 \mathrm{wt} \% \mathrm{Ti}+\mathrm{Ta}+\mathrm{Nb}+\mathrm{Hf}$, compared to $2.3-$ $5 \mathrm{wt} \% \mathrm{Al}$. During casting, these elements may segregate to a platelet phase form. These phases were usually found in the as-cast condition. In some cases, the platelet phases were found after a deviated process that lead to the rejection of these castings [8]. A review of the literature showed little documentation on the occurrence of platelet phases, other than TCP phases such as s or $\mu$. The platelet phases can usually be eliminated by process control, although the evidence suggests that small amounts of the platelet phases can be tolerated in today's turbine engines without degradation of mechanical properties. The $\eta$ phase has an HCP structure that is coherent with the FCC matrix in the mutual planes (0001)//(111), but generally exists as large platelets which can extend across grains. In addition to a change in the lattice spacing, a shift of the atomic planes changes the stacking sequence determining the $\gamma$ or $\eta$ phase. When the $\eta$ phase precipitates from 
the matrix, there has generally been some reduction in the mechanical properties. These phases are basically $\mathrm{Ni}_{3} \mathrm{Ti}(\mathrm{HCP})$ or $\mathrm{Ni}_{3} \mathrm{Nb}(\mathrm{BCT})$ and defined as GCP [9].

On the other hand, the TiC carbide, which has high Vickers hardness (29 - 34 $\mathrm{GPa})$, relatively low density $(4.91 \mathrm{~g} / \mathrm{cm})$ and a high melting temperature $\left(3067^{\circ} \mathrm{C}\right)$, is successfully synthesized through a process of producing carbon-coated titanium, under vacuum conditions at $1450^{\circ} \mathrm{C}$ [10]. The free energy to formation is $\Delta \mathrm{G}_{\mathrm{t}}{ }^{\circ}(\mathrm{TiC})=-44,600+3.16 \mathrm{~T}$ within the temperature range of $298-1150 \mathrm{~K}$, as reported in [11]. At a higher temperature range, between $2383-2593 \mathrm{~K}$, the stability of this carbide, $\mathrm{DG}_{\mathrm{t}}{ }^{\circ}(\mathrm{TiC})=-141,064+35.0 \mathrm{~T}$, improves and it is very difficult to decompound during a regular process of solidification and casting. This carbide can be created in Ni-base superalloys, and possibly does not dissolve during the metallurgical process of production.

Also, $\mathrm{V}_{2} \mathrm{C}$ carbide has high hardness (2660 knoop), a high density $\left(5.77 \mathrm{~g} / \mathrm{cm}^{3}\right)$ and a $2820^{\circ} \mathrm{C}$ melting point. Vanadium Carbide (VC) has a cubic phase and can be formed in the $<111>$ orientation. Although VC is thermodynamically stable, it converts to $\mathrm{V}_{2} \mathrm{C}$ at higher temperatures. The free energy of formation of this carbide is $\Delta \mathrm{G}_{\mathrm{t}}{ }^{\circ}(\mathrm{TiC})=-24,100+1.5 \mathrm{~T}$ within the temperature range of 1180 $1370 \mathrm{~K}$, as reported in [11]. Due to the mentioned characteristics of the carbides $\mathrm{TiC}$ and VC, and their high thermodynamic stability, they are formed in Ni-base alloy and have some probability to remain stable. Since Inconel 100 contains a low level of $\mathrm{V}, \mathrm{TiC}$ is apparently the most stable carbide in comparison to other $\mathrm{M}(\mathrm{Ni}, \mathrm{Cr}, \mathrm{Co}, \mathrm{Mo}, \mathrm{Al}, \mathrm{B}$ and $\mathrm{Zr}) \mathrm{C}$ carbides that could be created during the metallurgic process and dissolved during the heating of the ingot before pouring it into the casting mold.

Due to the high $\mathrm{Cr} / \mathrm{Ti} / \mathrm{Al}$ content, the two major phases present in IN100 are: ordered $\gamma^{\prime}\left(\mathrm{Ni}_{3} \mathrm{Al}\right.$ Type) phase embedded in a Face Centered Cubic (FCC) $\gamma$ as the solid-solution. Carbides and borides appear as minor phases, although they have a relatively high carbon content $(0.18 \%)$ compared to other Nickel base superalloys. The material properties of IN100 depend on a number of interrelated microstructural parameters, including the volume fraction of $\gamma$ to $\gamma$, grain size, elemental distribution, and precipitation of carbides and borides.

The current study presents a characterization and a failure analysis of Inconel 100 loaded samples and an examination of their fractography. Chemical analysis, optical metallography, SEM and EDS were used for the characterization of the unusual areas of fracture that were found on the samples.

\section{Experimental Work}

The alloy characterized in this study is commercial Inconel 100 after quantitative chemical analysis by ICP-and light element analysis, as presented in Table 1. The samples were bond shaped, machined to $55 \mathrm{~mm}$ total length, $25 \mathrm{~mm}$ gage length, $4 \mathrm{~mm}$ diameter (6D) and 3/8" UNC screw adapted to the grips. Some of the samples were heat treated as follows: $1080^{\circ} \mathrm{C}$ for 4 hours and air cooled, and $870^{\circ} \mathrm{C}$ for 12 hours followed by air cooling. Some of the samples remained as 
Table 1. Chemical compound of Inconel 100 (samples-BSEL Lab. and IN100 standard/MTS1001-section 2).

\begin{tabular}{|c|c|c|c|c|c|c|c|c|c|c|c|c|c|c|}
\hline Element & $\mathrm{Al}$ & B & Co & $\mathrm{Cr}$ & $\mathrm{Fe}$ & $\mathrm{Mn}$ & Mo & $\mathrm{P}$ & $\mathrm{Si}$ & $\mathrm{Ti}$ & $\mathrm{V}$ & $\mathrm{Zr}$ & $\mathrm{C}$ & $\mathrm{Ni}$ \\
\hline wt\% & 5.51 & 0.013 & 13.87 & 8.41 & 0.11 & 0.01 & 2.83 & $0.002 \max$ & 0.01 & 4.60 & 0.76 & 0.03 & 178 ppm & Rem. \\
\hline
\end{tabular}

Traces level of $\mathrm{Bi}, \mathrm{Pb}, \mathrm{Te}$ and $\mathrm{Tl}$ according to the standard.

cast for comparison. The samples were cleaned and loaded to $590 \mathrm{MPa}$ for rupture testing at $760^{\circ} \mathrm{C}$ and at room atmosphere. Optical metallography of the cross section of the sample close to the failed plane after the test rupture, as well as characterization and investigation of the failed surface, were carried out by optical microscopy and SEM-EDS techniques.

\section{Results}

In accordance with the rupture test for casting and production parts of Inconel 100 (IN100 Standard/MTS1001-section 6.5) were submitted to $590 \mathrm{MPa}$ at $760^{\circ} \mathrm{C}$ up to failure. As-cast samples failed after a few hours $(6 \mathrm{hrs}$.), and the heat-treated samples failed after 53 hours.

Figure 1 shows SEM images of the fracture surface for the as-cast sample (a) and the heat-treated sample (b). The round contour of the samples diameter in the gage length can be observed. No major differences were found in the SEM fractography at low magnification. At higher magnifications of the SEM image and by investigation of the surface it was found that the heat treatment induced a moderate change in the structure that can be observed in Figure 2. Most of the surface in the as-cast sample is characterized by cross cleavages, brittle fracture and small remaining micro cracks, in parallel to the platelet structures. In the heat-treated sample the same effect was found, but less spread over the failure surface and many more areas with small dimples were found.

Optical metallography of the samples preformed close to the cross section of the failure area showed "Chinese Scripture", which is well-known for carbides. These microstructures are presented in Figure 3. There is a correlation between the findings from the SEM image of the fracture area and from the optical metallography, according to the size of the so-called "Chinese Structure", but the amount of carbides on the surface seen in the optical image do not represent the amount of platelet fractures and cleavage that could be observed in the SEM fractography. In Figure 4, fracture cleavage of both samples as-cast and heat-treated can be observed; the figure is focused on a selected area is to emphasize the uncommon fracture in the alloy. EDS chemical analysis was carried out on an as cast sample in the area of the cleavages, as shown in Figure 5. The results show high concentrations of Ti, $\mathrm{V}$ and some Mo on the cleavage surface, while the $\mathrm{Al}$, $\mathrm{Cr}$ and $\mathrm{Ni}$ are absent in the cleavage area. Chemical mapping by EDS of the surface that is shown in Figure 4(a) is presented in Figure 6. The main difference between Figure 5 and Figure 6 is the contrast between the platelet surface and cross section lines of the parallel platelet observed by chemical mapping, and 


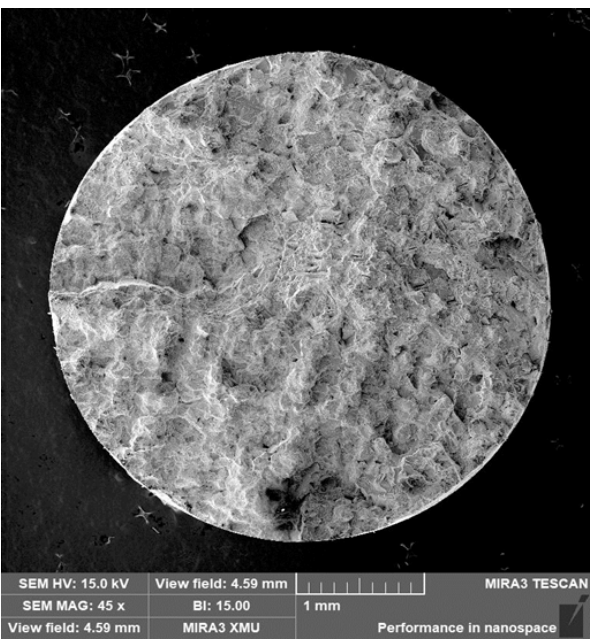

(a)

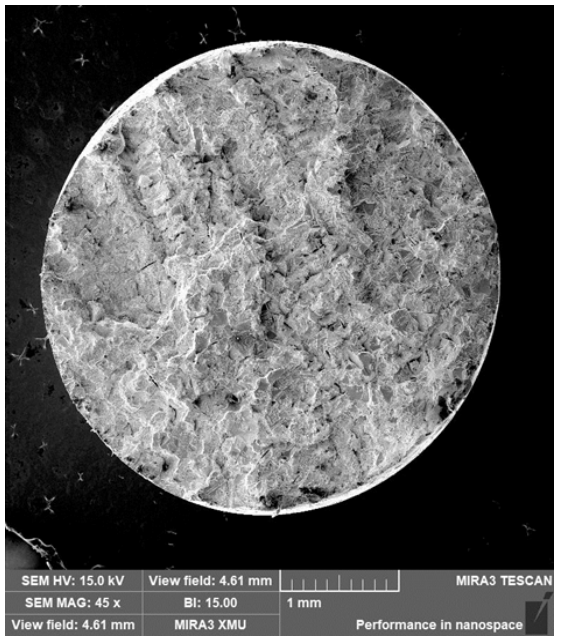

(b)

Figure 1. SEM fracture are images showing the round contour of the samples: surface of the as-cast sample (a), the heat-treated sample (b).

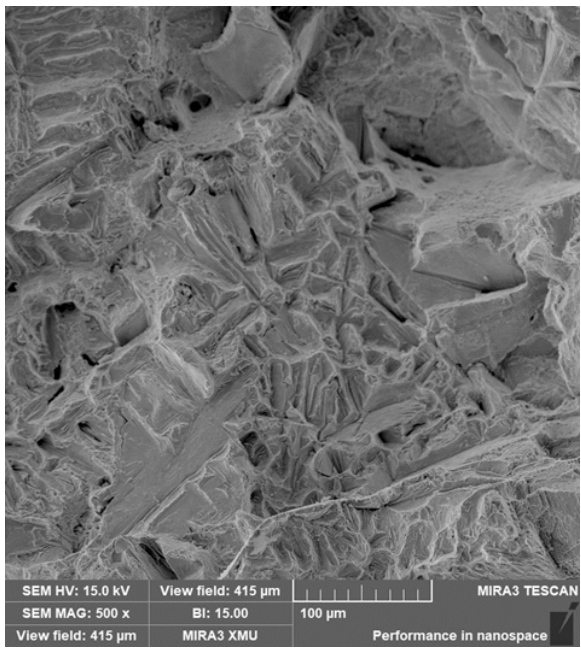

(a)

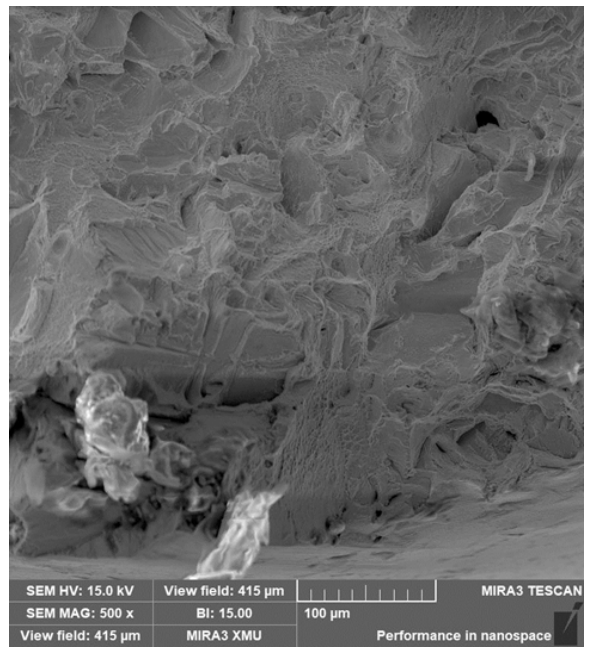

(b)

Figure 2. SEM fracture areas: surface of the as-cast sample with platelet structures (a) and the heat-treated sample with less platelet structures and small dimple areas (b).

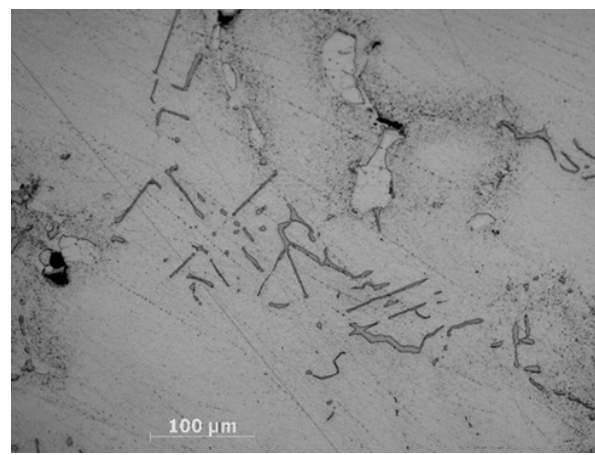

(a)

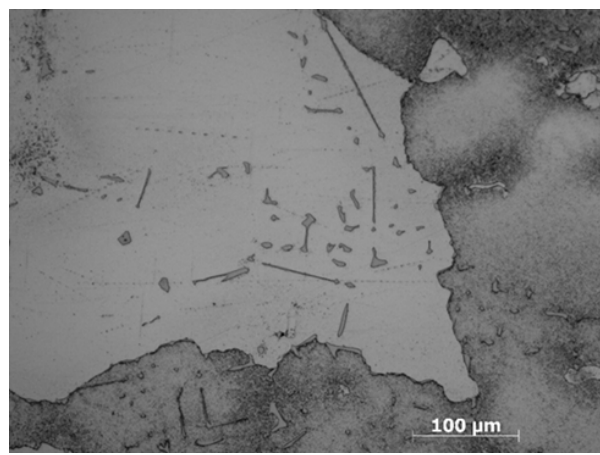

(b)

Figure 3. Optical metallography of the samples close to the cross section of the failure area (showing "Chinese Scripture"): as-cast sample (a) and the heat-treated sample (b). 


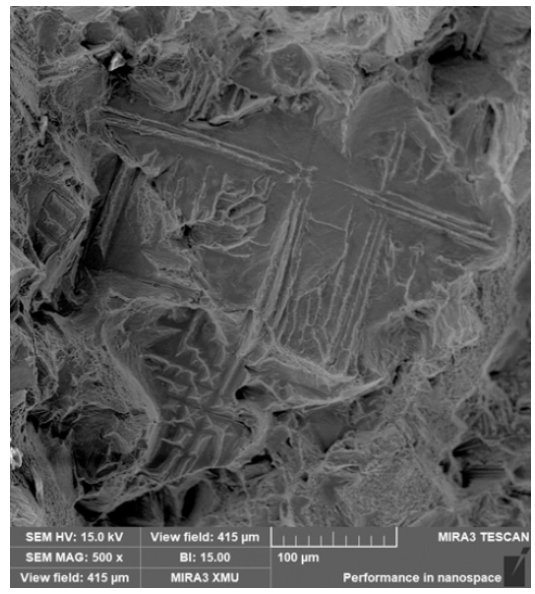

(a)

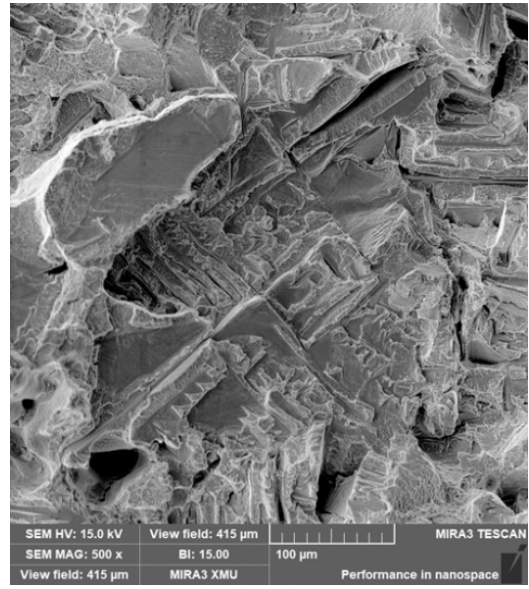

(b)

Figure 4. SEM image of selected area of the fracture: surface of the as-cast and heat-treated samples with platelet structures (a) and (b), respectively.

when using the EDS technique. The results show that the parallel platelets have different ordinated chemical composition formed during the thermodynamic process that could be attributed to the spinodal decomposition in the thermodynamic process. Although the carbon was measured in the EDS chemical mapping, its weight amount in the composition (0.18 wt\%) was too low to enable localizing its distribution with good accuracy. By using an EDS line scan crossing the parallel platelets, better results could be obtained, as shown in Figure 7. The counts in the plot are in weight percent (wt\%); the relation between the Ti peak and the $\mathrm{C}$ peak coordinate was calculated as two atoms of Ti for each atom of carbon. There is not a stoichiometric phase as $\mathrm{Ti}_{2} \mathrm{C}$ reported, but the mono-carbide $\mathrm{TiC}$ is well known and stable. Moreover, this is the only carbide of Ti that is recognized and known to be very brittle. One could assume that the concentration of $4.6 \mathrm{wt} \%$ of $\mathrm{Ti}$ in the alloy, is divided for the creation of a $\gamma$ phase as $\mathrm{Ni}_{3} \mathrm{Ti}$ and the creation of TiC, but, in fact, there is no rule of preference in the local amount of $\mathrm{Ti}$ in Inconel 100 from the thermodynamic point of view. The cleavage shown as a failure in Figure 5 and Figure 6 are the largest surfaces of the parallel platelets, and they represent the lowest energy path for the cracks to be developed. Small areas around the cleavage are shown as dimples and some are shown as brittle cracks.

\section{Discussion}

Inconel 100 has good mechanical properties at high temperatures. As-cast Inconel 100 stress rupture at $760^{\circ} \mathrm{C}$ and under $690 \mathrm{MPa}$ resisted up to 200 hours [12], while in the current failure analysis, as-cast samples resisted no longer than 6 hours. Only after heat treatment the resistance of the material improved and reached failure after 53 hours, which is very low in comparison to what would be expected for this alloy. Characterization of the fracture surfaces, indicated brittle fracture with small areas of dimples on the failure surface, but cleavage areas dominated, mostly in the as-cast sample, but also in the heat-treated sample. 

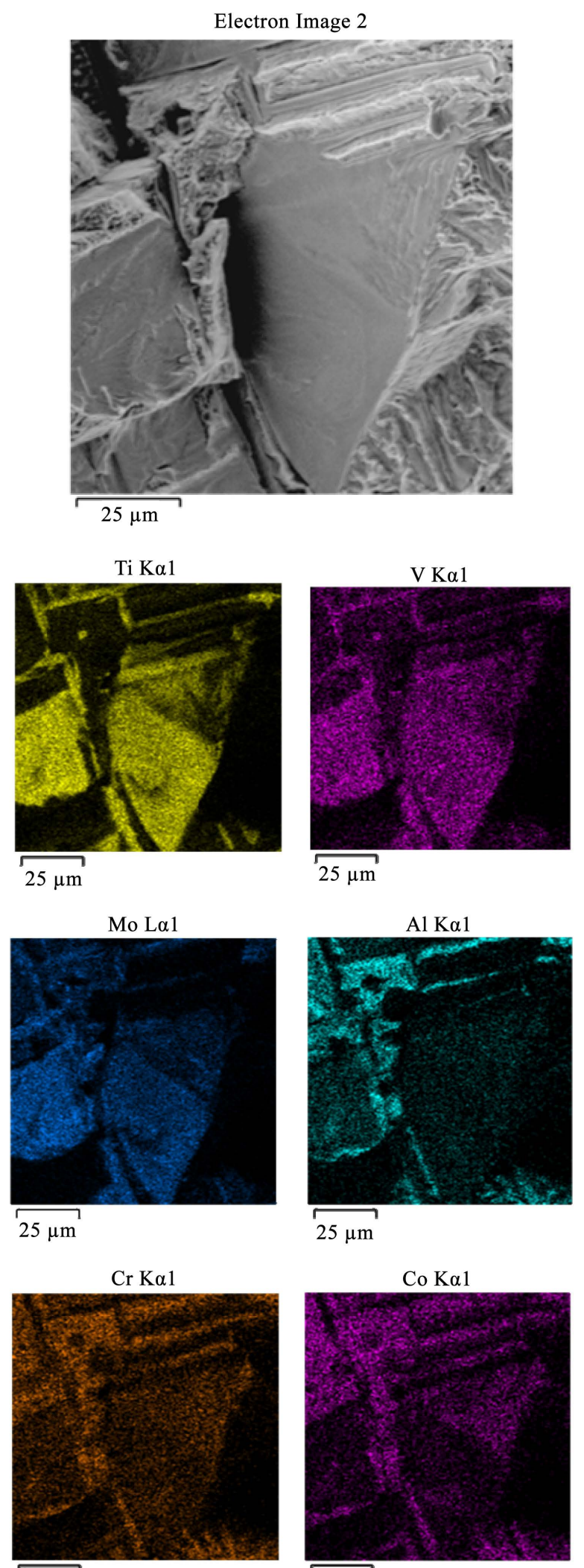

$25 \mu \mathrm{m}$

$\overline{25 \mu \mathrm{m}}$

Figure 5. SEM platelet structures image under EDS chemical mapping of the surface for the as-cast sample. The platelet zone showed high concentrations of $\mathrm{Ti}, \mathrm{V}$ and Mo, but no $\mathrm{Al}$ and less $\mathrm{Cr}$ and $\mathrm{Co}$. 


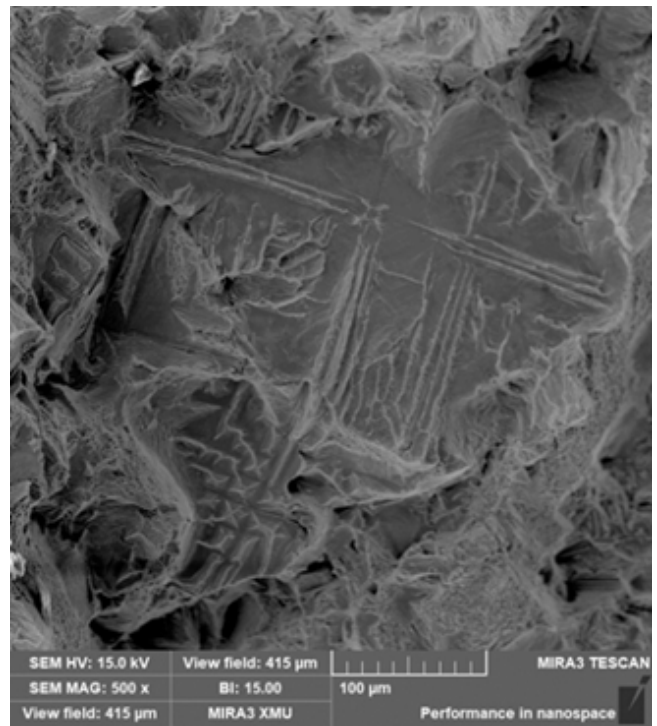

Ti K $\alpha 1$

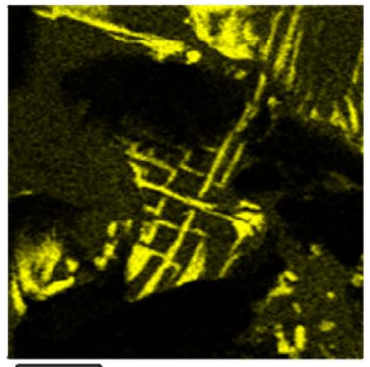

$\widehat{50 \mu \mathrm{m}}$

$\mathrm{Co} \mathrm{K} \alpha 1$

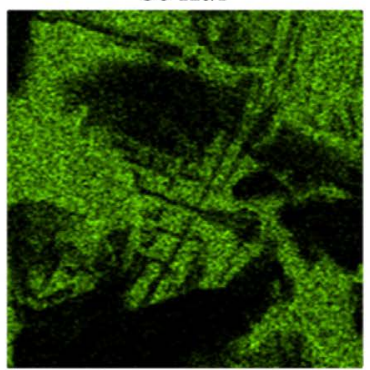

$\widehat{50 \mu \mathrm{m}}$

$\mathrm{Cr} \mathrm{K} \alpha 1$

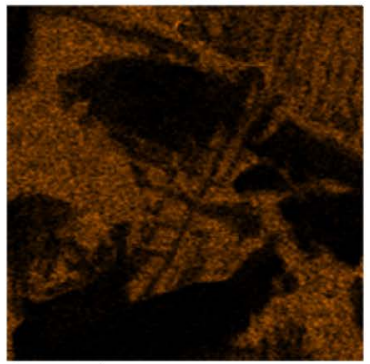

$50 \mu \mathrm{m}$
$\mathrm{V} \mathrm{K} \alpha 1$

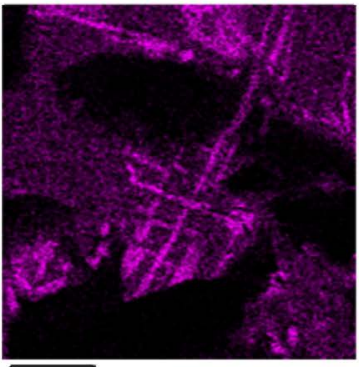

$\widehat{50 \mu \mathrm{m}}$

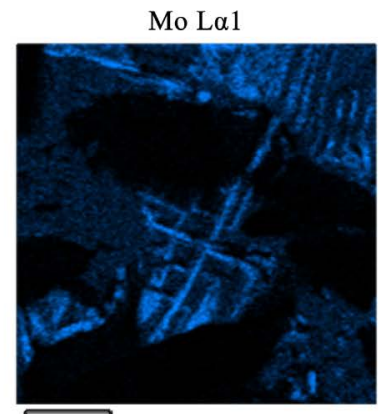

$50 \mu \mathrm{m}$

Al K $\alpha 1$

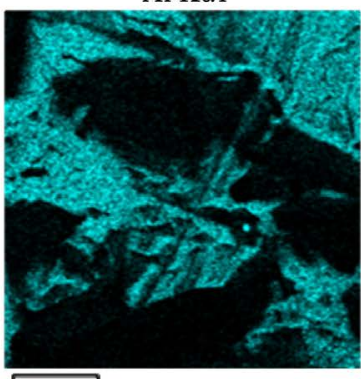

$5 \longdiv { 5 0 }$

Figure 6. SEM image of cross-platelet section structures under EDS chemical mapping on as-cast sample. 

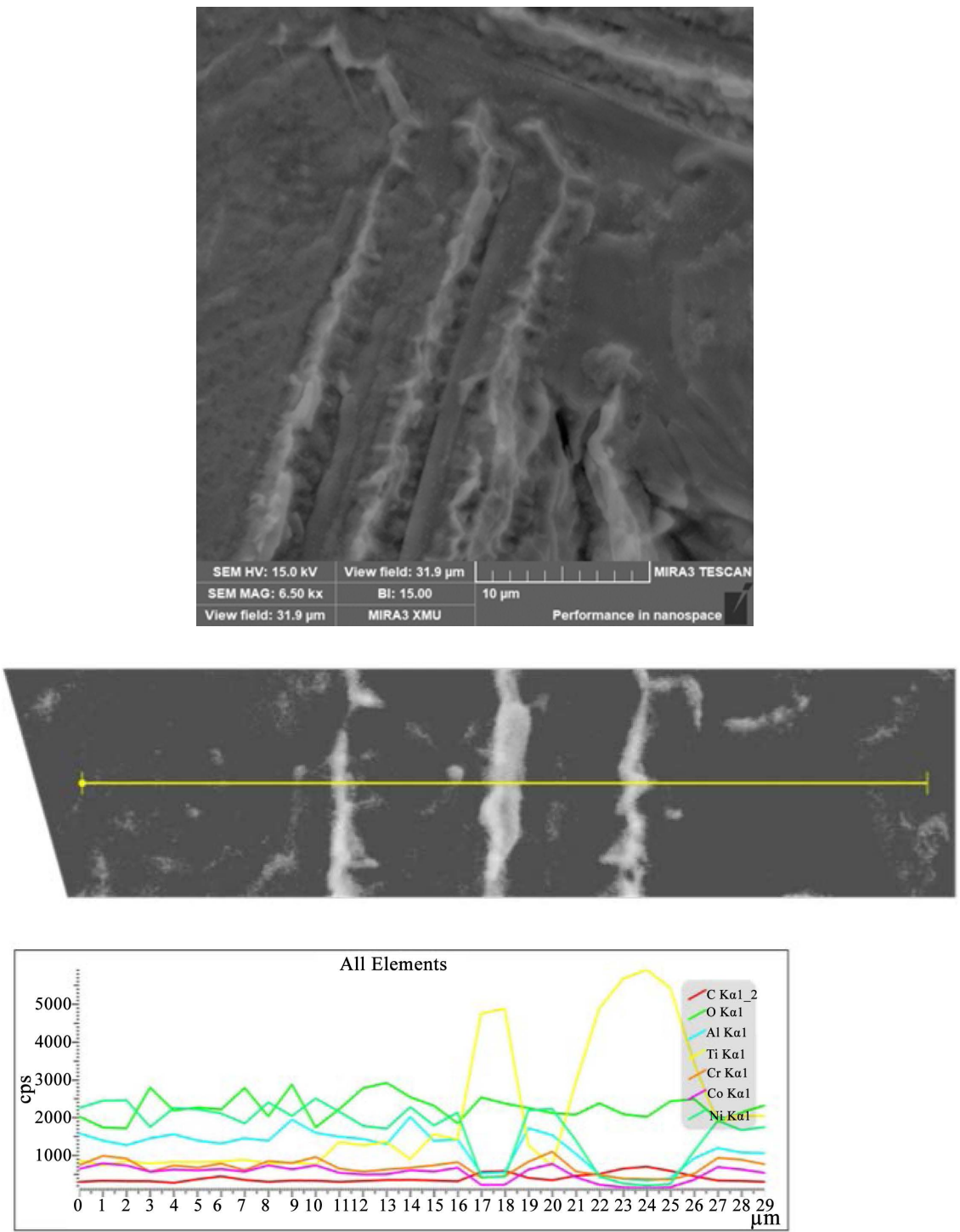

Figure 7. EDS line scan of the cross platelet structures in Figure 4(a). The counts of the $\mathrm{Ti}$ and $\mathrm{C}$ peak upwards, while the $\mathrm{Co}, \mathrm{O}, \mathrm{Al}$ and $\mathrm{Cr}$ counts peaks downwards. No major changes were found on the line scan of $\mathrm{Ni}$. The cross section lines showed high concentration of $\mathrm{Ti}, \mathrm{V}$ and $\mathrm{Mo}$, but no $\mathrm{Al}$ and less $\mathrm{Cr}$ and $\mathrm{Co}$.

Chemical mapping and a line scan of the fracture surface indicated that the platelets act as a source of the localized cleavages, and are predominantly rich in $\mathrm{Ti}$ and $\mathrm{C}$, as is shown in Figure 7. This leads to the conclusion that the weakness of the material was caused by the high amount of large carbides. These carbides are assumed to be TiC. TiC carbide, which has a relatively low density $(4.91 \mathrm{~g} / \mathrm{cm})$ and a high melting temperature $\left(3067^{\circ} \mathrm{C}\right)$, has a free energy to formation that can be calculated by $\mathrm{DG}(\mathrm{TiC})=-44,600+3.16 \mathrm{~T}$ within the temperature range of $298-1150 \mathrm{~K}$, as mentioned in the Introduction [11]. This carbide can be created in Ni-base superalloys, and possibly is difficult to dissolve during the metallurgical process of production due to its high thermodynamic stability. The size of the $\mathrm{TiC}$ that was shown in Figure 3 is larger than $100 \mu \mathrm{m}$, which is larger than 
the $\mathrm{TiC}$ reported elsewhere for Inconel 100, whose dimensions are only a few microns [5] [6] [13]. The size of the carbides dispersed in the material could not be attributed only to the casting process. The nominal size of the $\mathrm{TiC}$ created during solidification according to the metallography results reported over the years is less than $20 \mu \mathrm{m}$, and we assume the kinetics of formation and the local concentrations of the reaction elements are the main factors that affect to the size and shape of the carbides. Recently, the morphology of MC carbide has been observed to vary with melt heat treatment temperature in K465 nickel base superalloy which had been re-melted in a DTA (differential thermal analysis) instrument [14].

In specific cases, the stable carbide does not dissolve completely during the melting stage, prior to pouring the liquid metal, and it flows directly to the mold as small particles to be grown subsequently during the solidification. During the solidification, those carbides act as nuclei and enhance their size to over $150 \mu \mathrm{m}$, as was observed in the images in this study. It would seem that much more precaution should have been taken during the melting at the proper melting temperature to assure the fully liquid phase of the ingot.

\section{Conclusions}

This study presents a characterization and a failure analysis of Inconel 100 under a $760^{\circ} \mathrm{C}$ and $690 \mathrm{MPa}$ test to fail. The as-cast samples resisted no longer than 6 hours, while after heat treatment they resisted 53 hours, which is low compared to the expected duration for this alloy. Fractography examination, chemical analysis, optical metallography, SEM and EDS were used for the characterization of the unusual areas of fracture.

Most of the surface in the as-cast sample is characterized by cross cleavages, brittle fracture and small remaining micro-cracks, parallel to the platelet structures. In the heat-treated sample, the same effect was found, but less spread across the failure surface and many more areas with small dimples.

While it could be assumed that the concentration of $4.6 \mathrm{wt} \%$ of $\mathrm{Ti}$ in the alloy would be divided for the creation of $\gamma$ phase as $\mathrm{Ni}_{3} \mathrm{Ti}$ and the creation of $\mathrm{TiC}$, it appears that in Inconel 100 alloy there is no rule of preference in the local amount of Ti from the thermodynamic point of view.

In specific cases, the stable carbide does not dissolve completely during the melting before pouring the liquid metal, and it flows directly into the mold as small particles to be grown later during the solidification.

The short resistance reflected by low the experiment time to failure of the samples is attributed to the large $\mathrm{TiC}$ mono carbides that were found in the fracture plane and in the metallographic cross-section.

\section{Conflicts of Interest}

The authors declare no conflicts of interest regarding the publication of this paper. 


\section{References}

[1] ASM Specialty Handbook: Nickel, Cobalt, and Their Alloys (\#06178G) (2000) Davis J.R, Ed., ASM International Materials Park, Ohio, 293-331. https://www.asminternational.org/documents/10192/1849770/ACFA9DA.pdf

[2] Donachie, M.J. and Donachie, S.J. (2002) Superalloys-A Technique Guide. 2nd Edition, ASM International. https://doi.org/10.31399/asm.tb.stg2.9781627082679

[3] Aleksandra, J. (2013) Effect of Strengthening Additions on the Oxidation and Sulphidation Resistance of Cast Ni-Base Superalloys. Von der Fakultät für Maschinenwesen der Rheinisch-Westfälischen Technischen Hochschule Aachen zur Erlangung des akademischen Grades einer Doktorin der Ingenieurwissenschaften genehmigte Dissertation, Tag der mündlichen Prüfung: 01.07.2013.

[4] Siemens, A.G. (2011) Energy Sector, Gas Turbine SGT-2000E, Reliable, Robust, Flexible, Answer for Energy.

[5] El-Bagoury, N. and Mohsen, Q. (2011) Gamma Prime and TCP Phases and Mechanical Properties of Thermally Exposed Nickel-Base Superalloy. Phase Transitions, 84, 1108-1122. https://doi.org/10.1080/01411594.2011.582379

[6] Paraskevas, K., Aleksander, K., Dierk, R. and Baptiste, G. (2019) Influence of Composition and Precipitation Evolution on Damage at Grain Boundaries in a Crept Polycrystalline Ni-Based Superalloy. Acta Materialia, 166, 158-167.

https://doi.org/10.1016/j.actamat.2018.12.039

[7] Davis, J.R. (1997) ASM Specialty Handbook. Heat Resistant Materials. ASM International, Materials Park.

[8] Bouse, G.K. (1996) Eta( $\eta$ ) and Platelet Phases in Investment Cast Superalloys. In: Kissinger, R.D., Deye, D.J., Anton, D.L., Cetel, A.D., Nathal, M.V., Pollock, T.M. and Woodford, D.A., Eds., Superalloys, The Minerals, Metals \& Materials Society, Pittsburgh, 163-172.

https://www.tms.org/superalloys/10.7449/1996/Superalloys $1996 \quad 163 \quad 172 . p d f$

[9] Belan, J. (2016) GCP and TCP Phases Presented in Nickel-base Superalloys. Materials Today: Proceedings, 3, 936-941. https://doi.org/10.1016/j.matpr.2016.03.024

[10] Xie, Z., Deng, Y., Yang, Y., Su, H., Zhou, D., Liua, C. and Yang, W. (2017) Preparation of Nano-Sized Titanium Carbide Particles via a Vacuum Carbothermal Reduction Approach Coupled with Purification under Hydrogen/Argon Mixed Gas. RSC Advance, 7, 9037-9044. https://doi.org/10.1039/C6RA28264D

[11] Shatynski, S.R. (1979) The Thermochemistry of Transition Metal Carbides. Oxidation of Metals, 13, 105-118. https://doi.org/10.1007/BF00611975

[12] International Nickel Company Inc. (1962) Engineering Properties of In-100 Alloy. US Patent No. 3061426A. https://nickelinstitute.org/media/1707/in 100alloyengineeringproperties 483.pdf

[13] Belan, J. (2015) GCP and TCP Phases in Nickel-Base Superalloys. Materials Today. Proceedings, 3, 936-941. https://doi.org/10.1016/j.matpr.2016.03.024

[14] Wang, L.N., Sun, X.F. and Guan, H.R. (2017) Effect of Melt Heat Treatment on MC Formation in Nickel Base Superalloy K465. Results in Physics, 7, 2111-2117. https://doi.org/10.1016/j.rinp.2017.06.020 